\title{
Sign language acronyms
}

$\begin{array}{ll}\text { ASL } & \text { American Sign Language } \\ \text { CisSL } & \text { Cistercian Sign Language } \\ \text { DGS } & \text { German Sign Language (Deutsche Gebärdensprache) } \\ \text { HKSL } & \text { Hong Kong Sign Language } \\ \text { HSL } & \text { Hausa Sign Language } \\ \text { HZJ } & \text { Croatian Sign Language (Hrvatski Znakovni Jezik) } \\ \text { ISL } & \text { Israeli Sign Language } \\ \text { KSL } & \text { Kenyan Sign Language } \\ \text { LIBRAS } & \text { Brazilian Sign Language (Língua de Sinais Brasileira) } \\ \text { LIS } & \text { Italian Sign Language (Lingua Italiana dei Segni) } \\ \text { LIU } & \text { Jordanian Sign Language (Lughat il-Ishaara il-Urdunia) } \\ \text { LSC } & \text { Catalan Sign Language (Llengua de Signes Catalana) } \\ \text { NGT } & \begin{array}{l}\text { Sign Language of the Netherlands } \\ \text { (Nederlandse Gebarentaal) }\end{array} \\ \text { ÖGS } & \text { Austrian Sign Language (Österreichische Gebärdensprache) } \\ \text { PISL } & \text { Plains Indian Sign Language } \\ \text { TID } & \text { Turkish Sign Language (Türk İşaret Dili) }\end{array}$

